\title{
Rent

\section{Canadian breast cancer guidelines: Have they made a difference?}

\author{
Steven Latosinsky, Katherine Fradette, Lisa Lix, Karen Hildebrand, Donna Turner
}

$\infty \quad$ See related article page 785

\section{ABSTRACT}

Background: A principal objective of the Canadian Clinical Practice Guidelines for the Care and Treatment of Breast Cancer was to reduce the variation in the way that breast cancer was being treated. To evaluate whether this goal has been reached, we examined variations among surgeons for 4 measures of surgical care and tested for differences in province-wide rates and in variations among surgeons before and after the guidelines were released.

Methods: We studied a population-based cohort of 7022 women living in Manitoba in whom breast cancer was diagnosed from 1995 to 2003 inclusive. Demographic, tumour and treatment information was obtained from the Manitoba Cancer Registry. We examined 4 measures of care: breastconserving surgery, axillary assessment in invasive disease, axillary node dissection in noninvasive disease and the adequacy of axillary node dissection. Generalized linear models were used to test for significant variations in care among surgeons and to test for differences in province-wide rates and variations in these rates among surgeons before and after introduction of the guidelines.

Results: We found clinically significant variations in the province-wide rates of all 4 measures examined. These variations were statistically significant for all measures except axillary node dissection in noninvasive disease. No significant differences in either the province-wide rates or in variations in these rates among surgeons before and after introduction of the guidelines were found for any of the measures.

Interpretation: Our results suggest that the Canadian breast cancer guidelines are not meeting their stated objective. New strategies for guideline dissemination and implementation may be required.

CMAJ 2007:176(6):77I-6

7 he Canadian Clinical Practice Guidelines for the Care and Treatment of Breast Cancer, first published in February 1998, were developed to reduce the considerable variation in the way that breast cancer was being treated across Canada. ${ }^{1}$ The guidelines were principally disseminated through the print and online versions of CMAJ. A companion version for patients is available on the CMAJ Web site and through Health Canada, physicians' offices and various other organizations. There has been little objective assessment of the effectiveness of the guidelines, in large part because provincial information systems do not routinely monitor the consistency of clinical practice with respect to the guideline recommendations. ${ }^{2}$

The Manitoba Breast Cancer Outcomes Initiative was established as a quality-assurance initiative to provide insight into the patterns of treatment and outcomes of breast cancer care. In the present study, we used information collected by this initiative to examine the impact of the guidelines on the surgical treatment of breast cancer in Manitoba. The aims of our study were to determine whether variations exist among surgeons in 4 measures of surgical care; to test for an association between the introduction of the guidelines and province-wide rates for these 4 measures of care; and to test for an association between the introduction of the guidelines and variations in the procedure rates among surgeons. Although our study focuses on surgery, it can help us to understand how the introduction of these guidelines has influenced breast cancer treatment and to understand the effectiveness of current dissemination and implementation strategies.

\section{Methods}

This study was approved by the University of Manitoba Health Research Ethics Board. The population-based study cohort included all women living in Manitoba in whom in situ or invasive breast cancer was diagnosed from 1995 to 2003 inclusive. Patients were identified through the Manitoba Cancer Registry, which contains the records for more than $99.5 \%$ of all cases of cancer in Manitoba (Dr. Jeri Kostyra, formerly of CancerCare Manitoba: personal communication, 2005). Information on breast cancer staging, based on the American Joint Commission on Cancer (version 5 ), ${ }^{3}$ has been routinely collected for breast cancers diagnosed since Jan. I, I995. For women with multiple primary tumours, one was selected as the index tumour according to the following hierarchy: earliest diagnosis, highest stage and largest size.

The Manitoba Cancer Registry, which has been shown to contain highly accurate treatment data for cancer surgeries 
(unpublished data, 2006), was used to obtain demographic, tumour and treatment information for each case. The International Classification of Diseases (ninth revision, clinical modification [ICD-9-CM]) codes that were used to define the procedures are listed in Table I. We identified and included procedures that occurred up to 3 months before or up to I year after diagnosis. If a woman had multiple procedures in the breast, the most extensive procedure within I year of the diagnosis was included.

There was no ICD-9-CM code for sentinel lymph node biopsy during the study period; therefore, data for this procedure are not recorded in the Manitoba Cancer Registry. During the study period, only a limited number of surgeons offered sentinel lymph node biopsy, and, until 200I, most biopsies were performed in concert with axillary node dissection. Since 200I, sentinel lymph node biopsy has been recorded on medical claim forms under tariff code 0438 . An axillary assessment refers to patients who have had an axillary node dissection, sentinel lymph node biopsy or both procedures. An inappropriate axillary node dissection in ductal carcinoma in situ was defined as any axillary node dissection in the presence of breast-conserving surgery or where 6 or more nodes were identified following mastectomy.

Individual surgeons who were responsible for performing the procedures were identified through linkage of medical claims in the Manitoba Health data sets with Manitoba Cancer Registry data. Surgeon identity remained anonymous.

We examined 4 measures of care in this study: breastconserving surgery in stage I-II breast cancer; axillary assessment (axillary node dissection, sentinel lymph node biopsy or both) for all invasive cancers, excluding stage IV; adequacy of axillary node dissection $(<$ Io nodes identified following axillary node dissection) for stage I-III; and axillary node dissection in ductal carcinoma in situ or stage 0 . These measures and the related guideline recommendations (Appendix I) are available at www.cmaj.ca/cgi/content/full/ I58/3/DCI. We selected these aspects of surgical care based on the existence of specific guidelines and the availability of reliable data for evaluation.

For each of the 4 measures, the procedure rates for individual surgeons who operated on 12 or more breast cancer cases per year were examined for clinically important varia-

Table 1: Breast surgery procedures defined by ICD-9-CM codes

\begin{tabular}{lc} 
Procedure & ICD-9-CM code \\
\hline Breast-conserving surgery & $\begin{array}{l}85.12,85.21, \\
85.22,85.23\end{array}$ \\
$\begin{array}{l}\text { Axillary node dissection (“Regional node } \\
\text { dissection” in Manitoba Cancer Registry) }\end{array}$ & $40.3,40.51$ \\
$\begin{array}{l}\text { Simple mastectomy (removal of breast } \\
\text { only, not nodes) }\end{array}$ & $85.41,85.42$ \\
$\begin{array}{l}\text { Modified radical mastectomy (simple } \\
\text { mastectomy + axillary node dissection) }\end{array}$ & $85.43,85.44$ \\
$\begin{array}{l}\text { Radical mastectomy (includes removal of } \\
\text { chest wall - pectoralis major muscle) }\end{array}$ & $85.45-85.48$ \\
\hline
\end{tabular}

tions across the study period. We accounted for confounding due to access to radiation facilities by examining breastconserving surgery separately for Winnipeg and nonWinnipeg (e.g., rural) surgeons and patients.

The annual province-wide crude rates of breast cancer surgery and the coefficients of variation among surgeons in Manitoba were plotted for each measure from 1995 to 2003 to assess the presence of an inflection point following introduction of the guidelines in 1998 .

In order to determine whether there was a statistical association between the introduction of the guidelines and the province-wide rates of surgical care over time, we used a generalized linear regression model with generalized estimating equations ${ }^{4}$ to test for significant differences in the provincewide rates between the pre- (1995-I997) and post(1999-2003) guideline periods for each of the 4 measures (data from 1998 was excluded). This type of populationaverage model is appropriate to test for differences in the average rate of change over time.

We stratified the observations in the population-average models based on age, Regional Health Authority area of residence and pathology summary stage. The dependent variable was the number of events (breast-conserving surgery, axillary assessment, adequacy of axillary node dissection or axillary node dissection in ductal carcinoma in situ) in each population stratum.

We used a Poisson distribution to model axillary node dissection in ductal carcinoma in situ and a negative binomial distribution to model province-wide rates for the other 3 measures.

We used a generalized linear model with random surgeon effects to test for an association between guideline introduction and variations among surgeon rates over time. These subject-specific models were used to test for significant variations in surgery rates among surgeons and to test for significant differences in subject-specific surgical rates between the pre- and post-guideline periods for each measure. ${ }^{5}$ The Poisson distribution was selected to model surgeon rates for all measures because it provided the best fit to these data. Preliminary analyses of the data revealed little variation in surgeon-specific rates of change over time; therefore, a random-effects model with a random slope for year was not considered to be an appropriate choice to model these data.

We included the natural logarithm of the total population for each stratum as an offset variable in the populationaverage models, and the natural logarithm of the total population seen by each surgeon was included as an offset variable in the surgeon-specific models. When modelling breastconserving surgery, axillary assessment, adequacy of axillary node dissection and axillary node dissection in ductal carcinoma in situ, we defined the total population as the total number of breast-conserving surgeries (without follow-up mastectomy) and mastectomies performed, the total number of patients with stage I-III breast cancer, the total number of axillary node dissections performed and the total number of patients with ductal carcinoma in situ respectively.

Both the population-average and subject-specific generalized linear regression models initially contained the fixed ef- 
Table 2: Patient and tumour* characteristics

\begin{tabular}{|c|c|}
\hline Characteristic & $\begin{array}{c}\text { No. }(\%) \\
\text { of patients }\end{array}$ \\
\hline \multicolumn{2}{|l|}{ Age at diagnosis, yr } \\
\hline$\leq 39$ & 335 (5) \\
\hline $40-49$ & 1109 (16) \\
\hline $50-59$ & $1655(24)$ \\
\hline $60-69$ & $1558(22)$ \\
\hline $70-79$ & $1465(21)$ \\
\hline$\geq 80$ & $900(13)$ \\
\hline \multicolumn{2}{|l|}{ Year of diagnosis } \\
\hline 1995 & $783(11)$ \\
\hline 1996 & $766(11)$ \\
\hline 1997 & $734(10)$ \\
\hline 1998 & $763(11)$ \\
\hline 1999 & $818(12)$ \\
\hline 2000 & $771(11)$ \\
\hline 2001 & $803(11)$ \\
\hline 2002 & $792(11)$ \\
\hline 2003 & $792(11)$ \\
\hline \multicolumn{2}{|l|}{ Tumour stage } \\
\hline Tx & 491 (7) \\
\hline Tis & 805 (11) \\
\hline $\mathrm{T} 1$ & $3478(50)$ \\
\hline $\mathrm{T} 2$ & $1842(26)$ \\
\hline T3 & 211 (3) \\
\hline $\mathrm{T} 4$ & 195 (3) \\
\hline \multicolumn{2}{|l|}{ Nodal status } \\
\hline Node negative & $3776(54)$ \\
\hline Node positive & $1757(25)$ \\
\hline Unknown & $1489(21)$ \\
\hline \multicolumn{2}{|l|}{ Summary stage } \\
\hline 0 & $790(11)$ \\
\hline 1 & $2078(30)$ \\
\hline 2 & $2179(31)$ \\
\hline 3 & 312 (4) \\
\hline 4 & 216 \\
\hline Unknown & $1414(20)$ \\
\hline \multicolumn{2}{|l|}{ Surgical procedure } \\
\hline BCS† & $4890(70)$ \\
\hline BCS only & 3308 (47) \\
\hline Mastectomy & 3467 (49) \\
\hline Axillary node dissection & $5087(72)$ \\
\hline Sentinel lymph node biopsył & $166(2)$ \\
\hline
\end{tabular}

Note: $\mathrm{BCS}=$ breast-conserving surgery.

*American Joint Commission on Cancer (staging version 5).

twith or without subsequent mastectomy.

$\ddagger$ With or without subsequent axillary node dissection. fects of year, pre- or post-guideline period, and year by pre- or post-guideline period. If the interaction model term was not statistically significant at $\alpha=0.05$, then a more parsimonious model that contained main effects was specified.

\section{Results}

There were 7528 breast cancer cases recorded in the Manitoba Cancer Registry from 1995 to 2003 inclusive. Selecting one tumour per woman left 7022 patients in the cohort. Patient, tumour and treatment characteristics are summarized in Table 2.

The breast cancer surgery rates for individual surgeons indicated that there was wide variation for each of the 4 measures of care across the study period. Descriptive statistics for each measure are provided in Table 3. Of note, axillary node dissection in ductal carcinoma in situ was a relatively low-volume procedure, with a median of I4 cases per surgeon over the study period; however, the number of cases per surgeon varied from 6 to 77 . In conjunction with an inappropriate axillary node dissection in ductal carcinoma in situ, $70 \%$ and $30 \%$ of primary surgeries to the breast were mastectomies and breast-conserving surgeries respectively.

The subject-specific generalized linear regression models showed that there were statistically significant variations in care among surgeons for 3 of the 4 measures: breast-conserving surgery, axillary assessment and adequacy of axillary node dissection $(p<0.001)$. The variation of the random intercept was not significantly different from zero for axillary node dissection in ductal carcinoma in situ $(p=0.08)$.

The rates for each measure appeared to be unaffected by the introduction of the guidelines in 1998 except for the rate of axillary node dissection in ductal carcinoma in situ, which declined following release of the guidelines (Fig. I). The results of the population-average generalized linear regression models revealed no significant differences in province-wide rates between the pre- and post-guideline period for breast-conserving surgery $(p=0.09)$, axillary assessment $(p=0.76)$, axillary node dissection in ductal carcinoma in situ $(p=0.09)$ and adequacy of axillary node dissection $(p=0.54)$.

\begin{tabular}{|c|c|}
\hline Procedure & Mean (range), $\%$ \\
\hline \multicolumn{2}{|l|}{ Breast-conserving surgery } \\
\hline - Winnipeg cases & $53(23-100)$ \\
\hline - Non-Winnipeg (rural) cases & $24 \quad(8-45)$ \\
\hline Axillary assessment & $86(69-96)$ \\
\hline $\begin{array}{l}\text { Axillary node dissection in } \\
\text { ductal carcinoma in situ }\end{array}$ & $12(0-44)$ \\
\hline $\begin{array}{l}\text { Adequacy of axillary node } \\
\text { dissection }\end{array}$ & $28 \quad(6-54)$ \\
\hline
\end{tabular}


Consistent with what the province-wide rates showed, the subject-specific generalized linear regression models revealed that the rates by surgeon did not differ significantly between the pre- and post-guideline periods for axillary assessment $(p=0.12)$, axillary node dissection in ductal carcinoma in situ $(p=0.33)$ and adequacy of axillary node dissection $(p=0.78)$. However, the period main effect for rates of breast-conserving surgery by surgeon could not be interpreted as a simple difference between periods because the interaction of year by period was significant $(p=0.017)$. In particular, surgeon-specific rates of breastconserving surgery increased in the years before introduction of the guidelines but remained relatively constant after their introduction. Thus, there was a statistically significant point of inflection in breast-conserving surgery rates following guideline introduction, but not in the expected (increasing) direction.

Fig. 2 plots the coefficients of variation among surgeons for each measure of care over the study period and is included as an illustration of inter-surgeon variations over time. Guideline introduction was not associated with any changes in the coefficients of variation for the measures studied. The number of cases of ductal carcinoma in situ was small; consequently, the coefficient of variation for the measure of axillary node dissection in ductal carcinoma in situ was not included.

To investigate whether differences in variation between the pre- and post-guideline periods existed, subject-specific generalized linear regression models were specified separately for the 2 periods, and the variation of the random intercepts for the 2 periods were compared for each measure. None of the examined measures demonstrated differences in variation between the periods. Specifically, the measures of breast-conserving surgery, axillary assessment and adequacy of axillary node dissection each demonstrated significant variation among surgeons in both the pre- and post-guideline models, and axillary node dissection in ductal carcinoma in situ did not show significant variation among surgeons in either model.

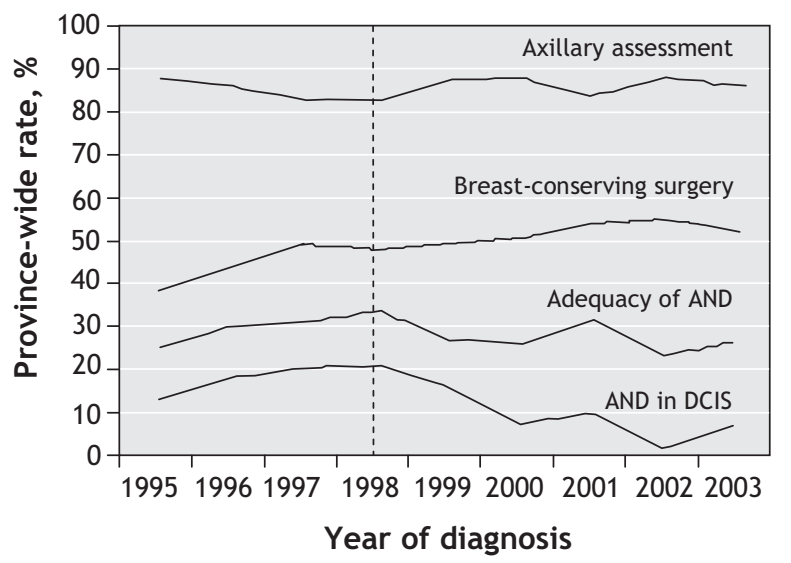

Fig. 1: Province-wide rates of breast cancer surgery, 1995 to 2003. AND = axillary node dissection, DCIS = ductal carcinoma in situ. Dashed vertical line indicates guideline introduction.

\section{Interpretation}

Despite evidence of clinically important variations in procedure rates among surgeons for all 4 of the measures of care studied and the statistically significant variations among surgeons for all but I of the measures (axillary node dissection in ductal carcinoma in situ), introduction of the Canadian breast cancer guidelines was not associated with any significant changes in province-wide procedure rates or in variations among surgeons in Manitoba. There may have been an improvement in the rate of axillary node dissection in ductal carcinoma in situ following introduction of the guidelines; however, this difference was not statistically significant, which may have been due to the small number of cases.

Previous studies using the same measures that we examined (breast-conserving surgery, ${ }^{6-8}$ axillary assessment in invasive ${ }^{9}$ or noninvasive ${ }^{10}$ disease and the adequacy of axillary node dissection ${ }^{11}$ ) have also reported variations in breast cancer surgery rates that were considered clinically important and that are likely to be unacceptable to health care providers, administrators and, most importantly, patients. In contrast, other studies have reported postguideline changes in surgical breast cancer care. ${ }^{12,13}$ The analyses performed in these studies, however, were based on 2 discrete points in time or on a comparison of regions with and without guidelines. ${ }^{14}$ By examining trends over time within the same region, our study was able to more fully examine whether the guidelines were related to changes in clinical practice patterns.

There are limits to what can be ascertained through administrative data. The Manitoba Cancer Registry is a highly accurate source of information about breast cancer surgeries (unpublished data, 2006); however, errors in coding can result in incorrect or unrecorded procedures. In this analysis,

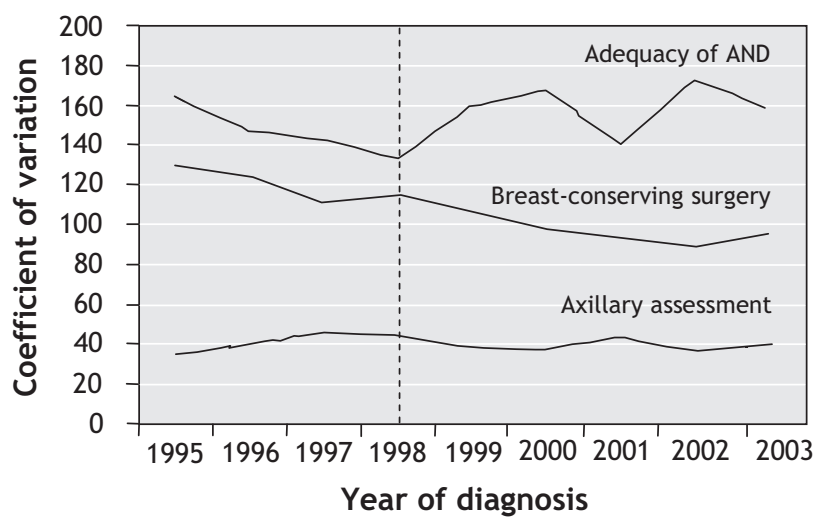

Fig. 2: Coefficients of variation among surgeons for 3 measures of surgical care from 1995 to 2003. Note: The number of cases of ductal carcinoma in situ was small; consequently, the coefficient of variation for the measure of axillary node dissection in ductal carcinoma in situ was not included. Dashed vertical line indicates guideline introduction. 
we were careful to prevent incorrect interpretations by examining cohorts of patients with similar access to radiotherapy for breast-conserving surgery and by setting a 6-node minimum for identifying an inappropriate axillary node dissection following a mastectomy for ductal carcinoma in situ. Despite this, some observed variation that is attributed to surgeon preferences may actually be the result of patient or tumour factors that cannot be accounted for using administrative data.

We acknowledge that the statistical power of our study to detect minimal clinically important differences could be low. From a technical perspective, in the design stage of the study we considered power calculations for detecting minimal clinically important differences. However, given that nonlinear random-effects models have rarely been used in similar epidemiological investigations, reasonable estimates for the level-I and level-2 variances and residual error, which are necessary to compute power for these models, were not available in the literature. From a more practical perspective, because we analyzed the entire population of breast cancer patients in Manitoba from 1995 to 2003, it is not possible to increase the number of observations available for analysis, as would be possible for survey or experimental data.

The Canadian breast cancer guidelines were rigorously developed and were disseminated through various media to promote uptake. Moreover, the guidelines have been regularly updated. Little has been done, however, to complete the life cycle of the guidelines in terms of implementation and evaluation of practice, as was recommended by Iscoe at their inception. ${ }^{15}$ Although there is some support in the literature for the ability of evidence-based guidelines to change patient outcomes and practices ${ }^{16}$ these changes typically occur only when guidelines are introduced in the context of rigorous evaluations or implementation strategies. ${ }^{17}$ Development and dissemination alone are insufficient to change practices ${ }^{18}$ Health Canada, as the main sponsor of the breast cancer guidelines, may want to reevaluate its role in ensuring effective implementation and evaluation, so that the guidelines have the desired effect of reducing variation in the way that breast cancer is treated across Canada.

The guidelines provide important information to health care providers and patients, and they make a significant contribution toward quality assurance in breast cancer care. The present study shows that the majority of breast cancer patients in Manitoba received surgical care consistent with what is recommended in the guidelines. However, important variations in care exist among surgeons. With the possible exception of axillary node dissection in ductal carcinoma in situ, the guidelines have not had an observable effect on the rate of breast cancer surgery or on the degree of variation among surgeons for the surgical care of breast cancer in Manitoba. These guidelines provide the best measure of acceptable practice; thus it is of specific interest that they be thoroughly implemented and consistently evaluated to provide all breast cancer patients with the best care possible.
This article has been peer reviewed.

From the Department of Surgical Oncology (Latosinsky) and the Epidemiology and Cancer Registry (Fradette, Hildebrand, Turner), CancerCare Manitoba; and the Departments of Surgery (Latosinsky) and Community Health Sciences (Latosinsky, Lix, Turner), University of Manitoba, Winnipeg, Man.

Competing interests: None declared.

Contributors: Steven Latosinsky was the primary author. With Karen Hildebrand, Katherine Fradette and Donna Turner, Steve Latosinsky came up with the conception and design of the study. Steven Latosinsky drafted the article with Karen Hildebrand and Katherine Fradette. Karen Hildebrand and Katherine Fradette were responsible for the acquisition of data. Lisa Lix and Donna Turner reviewed the article for important intellectual content. All of the authors contributed to the analysis and interpretation of data and approved the final version for publication.

Acknowledgements: We thank JoAnne Janzen for assistance with interpreting and reviewing Cancer Registry information and Wendy Fonseca-Holt for assistance with administrative data extraction.

We thank the CancerCare Manitoba Foundation for support of this project. Donna Turner was supported in part by a Senior Research Fellowship from the Canadian Institutes of Health Research, and Steven Latosinsky was provided salary support through the Rudy Falk Clinician-Scientist Award.

\section{REFERENCES}

I. Steering Committee on Clinical Practice Guidelines for the Care and Treatment of Breast Cancer. Clinical practice guidelines for the care and treatment of breast cancer. $C M A J$ I998; 158 (3 Suppl).I-83.

2. Health Canada. Progress report on cancer control in Canada. Ottawa: Health Canada; 2004. Cat no H39-4/50-2004E. Available: www.phac-aspc.gc.ca/publicat /prccc-relccc/pdf/F244_HC_Cancer_Rpt_English.pdf (accessed 2007 Jan 24).

3. Breast. In: Fleming ID, Cooper JS, Henson D, editors. American Joint Committee on Cancer cancer staging manual. 5 th ed. Philadelphia: Lippincott-Raven Publishers; 1997.

4. McCulloch CE, Searle SR. Generalized, linear, and mixed models. New York: John Wiley and Sons; 200I.

5. Fitzmaurice GM, Laird NM, Ware JH. Applied longitudinal analysis. New York: John Wiley and Sons; 2004

6. Iscoe NA, Goel V, Wu K, et al. Variation in breast cancer surgery in Ontario. CMA I994;150:345-52.

7. Guadagnoli E, Weeks JC, Shapiro CL, et al. Use of breast-conserving surgery for treatment of stage I and stage II breast cancer. J Clin Oncol I998;16:IOI-6.

8. Gaudette LA, Gao RN, Spence A, et al. Declining use of mastectomy for invasive breast cancer in Canada, I98I-2000. Can J Public Health 2004;95:336-40.

9. Bland KI, Scott-Conner CE, Menck H, et al. Axillary dissection in breast-conserving surgery for stage I and II breast cancer: a National Cancer Data Base study of patterns of omission and implications for survival. J Am Coll Surg 1999;I88: 586-95.

Io. Baxter NN, Virnig BA, Durham SB, et al. Trends in the treatment of ductal carcinoma in situ of the breast. J Natl Cancer Inst 2004;96:443-8.

II. Schaapveld M, Otter R, de Vries EG, et al. Variability in axillary lymph node dissection for breast cancer. J Surg Oncol 2004;87:4-I2.

I2. White V, Pruden M, Giles G, et al. The management of early breast carcinoma before and after the introduction of clinical practice guidelines. Cancer 2004; IOI: 476-85.

I3. McEvoy SP, Ingram DM, Byrne MJ, et al. Breast cancer in Western Australia: clinical practice and clinical guidelines. Med J Aust 2004;18I(6):305-9.

I4. Sawka C, Olivotto I, Coldman A, et al. The association between population-based treatment guidelines and adjuvant therapy for node-negative breast cancer. British Columbia/Ontario Working Group. Br J Cancer 1997;75:1534-42.

15. Iscoe NA. We may get this horse to water, but will it drink? CMAJ I998;158:345-6.

I6. Bahtsevani C, Uden G, Willman A. Outcomes of evidence-based clinical practice guidelines: a systematic review. Int J Technol Assess Health Care 2004;20:427-33.

I7. Grimshaw JM, Thomas RE, MacLennan G, et al. Effectiveness and efficiency of guideline dissemination and implementation strategies. Health Technol Assess 2004;8:iii-iv, I-72.

I8. Browman G. National guideline workshop backgrounder. The clinical practice guideline 'life cycle'. 2002 July I2. Available: http://209.217.127.72/cscc/pdf/priorities _pdf/CPG_LifeCycle.PDF (accessed 2007 Jan 30).

Correspondence to: Dr. Steven Latosinsky, Department of Surgery, Health Sciences Centre, Rm. GF-434, 820 Sherbrook St., Winnipeg MB R3A IRg; slatosinsky@hsc.mb.ca 
Appendix 1: Measures of care chosen to evaluate the effect of related Canadian breast cancer guidelines ${ }^{1}$

Measure

Breast-conserving surgery in stage I-II disease

Axillary assessment (axillary node dissection or sentinel lymph node biopsy) for invasive disease

Adequacy of axillary node dissection; $\geq 10$ nodes identified following axillary node dissection for stage I-II disease

Axillary node dissection in ductal carcinoma in situ
Guideline

Guideline 3. Mastectomy or lumpectomy? The choice of operation for clinical stages I and II breast cancer

"For patients with stage I and II breast cancer, breast-conserving surgery followed by radiotherapy is generally recommended. In the absence of special reasons for selecting mastectomy, the choice between breast conserving surgery and mastectomy can be made according to the patient's circumstances and personal preferences"

Guideline 4: Axillary dissection

"Removal and pathological examination of axillary lymph nodes should be standard procedure for patients with early, invasive breast cancer"

Guideline 4: Axillary dissection

"For accurate staging and to reduce the risk of recurrence in the axilla, level 1 and level 2 nodes should be removed. [... consistent removal of fewer than 10 nodes should lead to a review of surgical and pathological techniques]" *

Guideline 5: Management of ductal carcinoma in situ

"Axillary surgery, whether a full or limited procedure, should not be performed in women with ductal carcinoma in situ"

*Information in square brackets is not explicitly stated in the guideline but is contained in supporting evidence and rationale.

\section{ACCESS}

$C M A J$ is the only leading general medical journal that is free online. CMAJ.ca receives over 2 million hits per month of which two-thirds are from international readers. 